\title{
25 Research Square \\ Impact of the inpatient infectious disease consultations at a tertiary care university hospital
}

\section{Rami Waked ( $\square$ ramiwaked12@hotmail.com )}

Universite Saint-Joseph https://orcid.org/0000-0001-8280-6638

\section{Danielle Jaafar}

Centre Hospitalier Intercommunal de Villeneuve Saint Georges

Marie Chedid

Universite Saint-Joseph

Gebrael Saliba

Universite Saint-Joseph

Elie Haddad

Universite Saint-Joseph

Jacques Choucair

Universite Saint-Joseph

\section{Research}

Keywords: Infectious Disease specialist, Consultation services, Antibiotic stewardship, Antibiotic de-escalation, Inpatient treatment, Impact Assessment

Posted Date: November 19th, 2019

DOl: https://doi.org/10.21203/rs.2.17410/v1

License: (우 (i) This work is licensed under a Creative Commons Attribution 4.0 International License. Read Full License 


\section{Abstract}

The role of the infectious disease specialist continues to evolve. The purpose of this study is to demonstrate the value of infectious disease consultation in the inpatient setting.METHODS This is a prospective cohort study that took place in a tertiary care university hospital. During the period from April to June 2016, 224 cases of patients receiving antibiotics in the hospital with the request of an infectious diseases' consultation, were evaluated. The following variables were assessed: the referring department, purpose of the consultation, the antibiotic used before requesting the infectious diseases consultation, the antibiotic modifications after the infectious disease's visit (changing the type, dose or range of the antibiotic when applicable, modifying the duration of antibiotic use), whenever the antibiotic usage was switched to a mono or bi-therapy.RESULTS The most frequent requesting departments were Oncology (23.2\%) and Urology (21.4\%). The purpose of the consultations was diagnosis (29\%), therapy (41\%), both diagnosis and therapy (21\%), and prophylaxis (9\%). An infectious diseases consultation was given at a rate of 4.9 consultations per 100 hospitalized patients. Antibiotic was discontinued in $14.7 \%$ of cases. There was no indication for the antibiotic treatment in $11.6 \%$ of cases. Modifying the antibiotic therapy was done in $25.4 \%$ of cases. Adjusting the antibiotic dosage was done in only one case. Carbapenem antibiotics were discontinued in $31.6 \%$ of cases and Quinolones discontinuation accounted for $22.7 \%$ of cases.CONCLUSION Infectious disease consults contributed to the optimization of the diagnostic and therapeutic approaches for suspected or confirmed infections in hospitalized patients.

\section{Background}

Global antimicrobial resistance is growing and poses a public health threat. (1) Patients with infections caused by multidrug resistant bacteria have a higher risk of poor outcomes and death compared to patients with nonresistant bacteria. (2) The rate of multi-drug resistant bacteria is increasing while new antimicrobial drugs are not being developed as rapidly. (3) Prolonged and misuse of antibiotics in the healthcare setting has been demonstrated to increase the spread of resistant bacteria. (4)

Antibiotic stewardship programs (ASPs) are programs that optimize antibiotic usage. They are defined by the Infectious Diseases Society of America as "coordinated interventions designed to improve and measure the appropriate use of antimicrobials by promoting the selection of the optimal antimicrobial drug regimen, dose, duration of therapy and route of administration". (5) Several studies reported the importance of such programs to decrease the economic cost and improve effectiveness of the antibiotic usage. $(6,7)$ The role of the infectious disease (ID) specialist has been constantly evolving during the past decade. (8) The ID consultant is not only required to assist in the diagnosis, management and treatment of patients, but also to manage the hospital's infection control. $(9,10)$

The aim of this study is to emphasize the role of infectious disease specialists in providing consultations to patients admitted to a tertiary care hospital.

\section{Methods}

This is a prospective cohort study that took place in a tertiary care university hospital located in Beirut, Lebanon. This hospital accounts for a total of 430 care beds. The analysis was conducted on a period of 3 months from April to June 2016. During the study period, the ID department consisted of 3 full-time ID consultants and two 
fellow residents. The ID consultations are typically initiated by a primary ("attending") physician. The antibiotic control policy of the hospital is that broad-spectrum antimicrobials are restricted, and their use requires approval by an infectious disease physician.

The population studied was all adult patients (18 years and older) that were admitted during that period (April to June 2016) with an infection (primary or secondary) for whom an initial formal ID consultation request was made. All stays transferred to the ID department were excluded from this study. Only adult patients receiving antibiotics were selected. There was no direct patient approach and cases were followed through an electronic medical record. Each unique admission was considered as the unit of analysis. There were 224 cases during that period. The medical committee of the hospital (Hotel Dieu de France, Beirut, Lebanon) approved this study.

The electronic and paper medical records (DX care version 7.7.2) were assessed between April to June 2016 searching for an infectious disease consultation. The following variables were collected using a standardized data collection form: the referring department, purpose of the consultation, the antibiotic used before the infectious diseases consultation was requested, the antibiotic modifications after the infectious disease's visit (changing the type, dose or range of the antibiotic when applicable, modifying the duration of antibiotic use), whenever the antibiotic usage was switched to a mono or bi-therapy. All analyses were performed using Excel version 16.0 (Microsoft Corporation).

\section{Results}

During the study period, 224 cases of patients receiving antibiotics for an infection in the hospital with the request of an ID consultation, were evaluated. The mean age of the population was 63 years with a standard deviation of 17.9 and a median of 67 . The characteristics of the population can be found in table 1 . The most frequent requesting from medical departments was Oncology (52 patients) and the most frequent requesting from surgical departments was Urology (48 patients).

The following results were obtained:

The purpose of the consultations was diagnosis (29\%), therapy (41\%), both diagnosis and therapy $(21 \%)$, and prophylaxis (9\%). An ID consultation was given at a rate of 4.9 consultations per 100 hospitalized patients.

Antibiotic was discontinued in $14.7 \%$ (33 patients) of cases. There was no indication for the antibiotic treatment in $11.6 \%$ (26 patients) of cases. Modifying the antibiotic therapy was done in $25.4 \%$ ( 57 patients) of cases (whenever empirically, after the results of a culture, or based on guidelines).

Changing to a broader spectrum antibiotic was carried in 23 patients whereas changing to an antibiotic with a narrower spectrum of action was conducted in 29 cases. Adjusting the antibiotic dosage was done in only one case. Carbapenem antibiotics were discontinued in $31.6 \%$ of cases (31 out of 98 patients) and Quinolones discontinuation accounted for $22.7 \%$ of cases ( 5 out of 22 patients). Prolonging or shortening the duration of the antibiotic therapy was carried in 7 and 13 cases respectively. A dual antibiotic therapy was indicated in $3.57 \%$ of patients ( 8 cases). Changing the treatment to a monotherapy was performed in $54.1 \%$ ( 13 out of 24 cases). Antibiotic was already started in 132 cases (59\%) before an ID consultation was requested. 87 (39\%) cases were on antibiotics listed in the restricted antimicrobial list of the hospital. Details are shown in table 2. The top referring departments are detailed in table 3 . ID diagnosis are shown in chart 1. 


\section{Discussion}

This study performed over a short period of time shows the impact of the antibiotic stewardship programs and ID consultations on the reduction of the inpatient antibiotic consumption. The percentage of antibiotic discontinuation obtained $(14.7 \%)$ was slightly lower than the one seen in other studies. $(11,12)$ The most frequent requests for ID consultations came from the Oncology department, probably reflecting the complexity and disease severity of these patients.

The population in this study shows that the most common sites of infection were urinary (32\%) followed by pulmonary/ENT infections (18\%) and skin and soft tissue infections (17\%) respectively. The rate of ID consults per admission (4.9/100 admissions) is comparable to the one in other studies. (13)

There is a rise in the multidrug resistant germs especially in the hospital setting. (14-17) Prior antimicrobial therapy, especially with a broad-spectrum agent, has been demonstrated to be a risk factor for multi-drug resistant infections. (16) A multidrug resistant infection is associated with an increased mortality rate. $(16,18) \mathrm{A}$ wide variety of nosocomial infections may occur in patients during their stay in the hospital. This study demonstrates the importance of the infectious disease consultation in preventing these complications: $14.7 \%$ had their antibiotic discontinued, $25.4 \%$ had an antibiotic modification, carbapenem and quinolones usage was reduced.

This study features the importance of the infectious disease consultation in patients receiving antibiotics during their hospitalization. It highlights the discontinuation in antibiotic treatment when not indicated, the adjustments brought to the treatment and to its duration. It also demonstrates the competence of the infectious diseases specialists in sparing the antibiotics with broad spectrum of action (specially the carbapenem). Protocols for antibiotic use for the most frequently encountered conditions should be implemented to reduce the dependency on ID advice.

The various purposes of ID consultations shown in this study illustrates the diversity of their work: from antibiotic prophylaxis, antibiotic stewardship, diagnosis to individual patient management.

Several articles in the literature describe the importance of the ID consultants' activities and roles in the hospital. $(13,19)$ They play a major role in the diagnosis, optimal use of antimicrobials and prevention of infections in certain populations.

There are some limitations to this study: One limitation is that it was conducted at a single center, and the results may not apply to other settings with different consultation styles. It did not evaluate the cost effectiveness nor the outcome of patients. This study lacks to determine the effect of the ID consultations' intervention on patients' bacterial colonization.

\section{Conclusion}

Infectious disease consultation in patients receiving antibiotics during their hospitalization is very important in terms of adjusting the treatment and its duration. Infectious disease specialists contribute to optimization of the diagnostic and therapeutic approaches for suspected or established infections. Our data shows the diversity of 
work of ID specialists. ID clinicians currently have challenging work that requires a considerable knowledge of infectious diseases and frequent interaction with other subspecialists and clinicians.

\section{List Of Abbreviations}

ASPs: Antibiotic stewardship programs

ID: Infectious disease

ENT: Ear Nose Throat

\section{Declarations}

Ethics approval and consent to participate:

The medical committee of the hospital (Hotel Dieu de France, Beirut, Lebanon) approved this study.

Consent for publication:

Not applicable.

Availability of data and materials:

The datasets used and/or analyzed during the current study are available from the corresponding author on reasonable request.

Competing interests:

The authors declare that they have no competing interests

Funding source:

This research did not receive any specific grant from funding agencies in the public, commercial, or not-for-profit sectors

Authors' contributions:

DJ collected the data. RW carried the sequence alignment and drafted the manuscript. DJ and EH helped to draft the manuscript. MC participated in the design of the study. JC and GS conceived the study and participated in its design and coordination. All authors read and approved the final manuscript.

Acknowledgements:

Not applicable.

\section{References}

1. A Call for Action: The Application of the International Health Regulations to the Global Threat of Antimicrobial Resistance [Internet]. [cited 2019 Sep 12]. Available from: 
https://www.ncbi.nlm.nih.gov/pmc/articles/PMC3079636/

2. WHO | Antimicrobial resistance: global report on surveillance 2014 [Internet]. WHO. [cited 2019 Aug 10]. Available from: http://www.who.int/drugresistance/documents/surveillancereport/en/

3. Boucher HW, Talbot GH, Bradley JS, Edwards JE, Gilbert D, Rice LB, et al. Bad bugs, no drugs: no ESKAPE! An update from the Infectious Diseases Society of America. Clin Infect Dis Off Publ Infect Dis Soc Am. 2009 Jan 1;48(1):1-12.

4. Levy SB, Marshall B. Antibacterial resistance worldwide: causes, challenges and responses. Nat Med. 2004 Dec;10(12 Suppl):S122-129.

5. Antimicrobial Resistance [Internet]. [cited 2019 Aug 10]. Available from: https://www.idsociety.org/policy-advocacy/antimicrobial-resistance/

6. Current evidence on hospital antimicrobial stewardship objectives: a systematic review and meta-analysis The Lancet Infectious Diseases [Internet]. [cited 2019 Sep 12]. Available from:

https://www.thelancet.com/journals/laninf/article/PIIS1473-3099(16)00065-7/fulltext

7. Dik J-WH, Vemer P, Friedrich AW, Hendrix R, Lo-Ten-Foe JR, Sinha B, et al. Financial evaluations of antibiotic stewardship programs-a systematic review. Front Microbiol [Internet]. 2015 Apr 16 [cited 2019 Aug 10];6. Available from: https://www.ncbi.nlm.nih.gov/pmc/articles/PMC4399335/

8. Eickhoff TC. Whither Infectious Diseases? Some Data at Last. :4.

9. Hamory BH, Hicks LL. Infectious disease manpower in the United States-1986. 2. Changes in practice patterns over time and training needs. Manpower and Training Committee, Infectious Diseases Society of America. J Infect Dis. 1992 Feb;165(2):218-23.

10. McGowan JE. The infection control practitioner: An action plan for the 1990s. Am J Infect Control. 1990 Feb 1;18(1):29-39.

11. Brink AJ, Messina AP, Feldman C, Richards GA, Becker PJ, Goff DA, et al. Antimicrobial stewardship across 47 South African hospitals: an implementation study. Lancet Infect Dis. 2016 Sep 1;16(9):1017-25.

12. Boyles TH, Whitelaw A, Bamford C, Moodley M, Bonorchis K, Morris V, et al. Antibiotic Stewardship Ward Rounds and a Dedicated Prescription Chart Reduce Antibiotic Consumption and Pharmacy Costs without Affecting Inpatient Mortality or Re-Admission Rates. PLoS ONE [Internet]. 2013 Dec 9 [cited 2019 Nov 6];8(12). Available from: https://www.ncbi.nlm.nih.gov/pmc/articles/PMC3857167/

13. Schlesinger Y, Paltiel O, Yinnon AM. Analysis and impact of infectious disease consultations in a general hospital. J Hosp Infect. 1998 Sep;40(1):39-46.

14. Yim J, Smith JR, Rybak MJ. Role of Combination Antimicrobial Therapy for Vancomycin-Resistant Enterococcus faecium Infections: Review of the Current Evidence. Pharmacother J Hum Pharmacol Drug Ther. 2017;37(5):579-92.

15. Fernando SA, Gray TJ, Gottlieb T. Healthcare-acquired infections: prevention strategies. Intern Med J. 2017;47(12):1341-51.

16. Cerceo E, Deitelzweig SB, Sherman BM, Amin AN. Multidrug-Resistant Gram-Negative Bacterial Infections in the Hospital Setting: Overview, Implications for Clinical Practice, and Emerging Treatment Options. Microb Drug Resist. 2016 Feb 11;22(5):412-31.

17. Boyanova L, Mitov I. Antibiotic resistance rates in causative agents of infections in diabetic patients: rising concerns. Expert Rev Anti Infect Ther. 2013 Apr;11(4):411-20. 
18. Falagas ME, Tansarli GS, Karageorgopoulos DE, Vardakas KZ. Deaths Attributable to Carbapenem-Resistant Enterobacteriaceae Infections. Emerg Infect Dis. 2014 Jul;20(7):1170-5.

19. Sexton DJ, Corey GR, Ingram CW, Morris VM, Haywood HB. Consultation in university-based and communitybased infectious disease practices: a prospective study. Clin Infect Dis Off Publ Infect Dis Soc Am. 1995 Feb;20(2):391-3.

\section{Tables}

Table 1: Characteristics of the 224 patients followed by the infectious disease specialist during this study

\begin{tabular}{|l|l|}
\hline Characteristics & Number of patients \\
\hline Neoplasm $^{\mathrm{a}}$ & 90 \\
\hline Arterial hypertension & 67 \\
\hline Diabetes & 40 \\
\hline Chronic kidney disease & 17 \\
\hline End stage renal disease & 17 \\
\hline Immunosuppression $^{\mathrm{b}}$ & 7 \\
\hline
\end{tabular}

a- Neoplasm includes solid and hematologic cancers; b- Immunosuppression consisted of patients treated for Crohn's disease, renal transplant, myasthenia gravis and a case of severe combined immunodeficiency

Table 2: Different characteristics of the 224 patients receiving antibiotics followed during their stay in the hospital 


\begin{tabular}{|c|c|c|c|c|c|c|}
\hline & $\begin{array}{l}\text { Antibiotic } \\
\text { discontinuation }\end{array}$ & $\begin{array}{l}\text { Changing } \\
\text { the } \\
\text { antibiotic } \\
\text { class }\end{array}$ & $\begin{array}{l}\text { Carbapenem } \\
\text { discontinuation }\end{array}$ & $\begin{array}{l}\text { Quinolone } \\
\text { discontinuation }\end{array}$ & $\begin{array}{l}\text { Changing to an } \\
\text { antibiotic with a } \\
\text { broader spectrum } \\
\text { of action }\end{array}$ & $\begin{array}{l}\text { Changing to an } \\
\text { antibiotic with a } \\
\text { narrower } \\
\text { spectrum of } \\
\text { action }\end{array}$ \\
\hline $\begin{array}{l}\text { No (No. } \\
\text { (\%) of } \\
\text { cases) }\end{array}$ & $190(84.8)$ & $167(74.5)$ & 67 (68.3) & $17(77.2)$ & 201 (89.7) & 195 (87) \\
\hline $\begin{array}{l}\text { Yes } \\
\text { (No. } \\
\text { (\%) of } \\
\text { cases) }\end{array}$ & 33 (14.7) & $57(25.4)$ & 31 (31.6) & 5 (22.7) & $23(10.2)$ & 29 (13) \\
\hline $\begin{array}{l}\text { Total } \\
\text { (No. of } \\
\text { cases) }\end{array}$ & 224 & 224 & 98 & 22 & 224 & 224 \\
\hline
\end{tabular}




\begin{tabular}{|l|l|l|l|l|l|l|l|l|}
\hline & $\begin{array}{l}\text { Antibiotic } \\
\text { dosage } \\
\text { adjustment }\end{array}$ & $\begin{array}{l}\text { Prolonging } \\
\text { the } \\
\text { duration } \\
\text { of } \\
\text { treatment }\end{array}$ & $\begin{array}{l}\text { Shortening } \\
\text { the } \\
\text { duration of } \\
\text { treatment }\end{array}$ & $\begin{array}{l}\text { Antibiotic } \\
\text { not } \\
\text { indicated }\end{array}$ & $\begin{array}{l}\text { Dual } \\
\text { antibiotic } \\
\text { needed } \\
\text { instead of } \\
\text { monotherapy }\end{array}$ & $\begin{array}{l}\text { Monotherapy } \\
\text { needed } \\
\text { instead of } \\
\text { dual } \\
\text { antibiotic } \\
\text { therapy }\end{array}$ & $\begin{array}{l}\text { Antibiotic } \\
\text { already } \\
\text { started } \\
\text { before ID } \\
\text { consult }\end{array}$ & $\begin{array}{l}\text { Antibiotic } \\
\text { used listed } \\
\text { in the } \\
\text { restricted } \\
\text { antimicrobial } \\
\text { list of the } \\
\text { hospital }\end{array}$ \\
\hline $\begin{array}{l}\text { No } \\
\text { (No. } \\
\text { (\%) of } \\
\text { cases) }\end{array}$ & $223(100)$ & $217(96.8)$ & $211(94.2)$ & 198 & $216(96.4)$ & $211(94)$ & $92(41)$ & $137(61.1)$ \\
\hline $\begin{array}{l}\text { Yes } \\
\text { (No. } \\
\text { (\%) of } \\
\text { cases) }\end{array}$ & $1(0)$ & $7(3.1)$ & $13(5.8)$ & $26(11.6)$ & $8(3.57)$ & $13(5.8)$ & $132(59)$ & $87(38.8)$ \\
\hline $\begin{array}{l}\text { Total } \\
\text { (No. } \\
\text { of } \\
\text { cases) }\end{array}$ & 224 & 224 & 224 & 223 & 224 & 224 & 224 & 224 \\
\hline
\end{tabular}

Table 3: Number of infectious disease consultations per referring department 


\begin{tabular}{|l|l|l|l|}
\hline $\begin{array}{l}\text { Referring } \\
\text { department }\end{array}$ & $\begin{array}{l}\text { Total number of } \\
\text { patients }\end{array}$ & $\begin{array}{l}\text { Referring } \\
\text { department }\end{array}$ & $\begin{array}{l}\text { Total number of } \\
\text { patients }\end{array}$ \\
\hline Oncology & 52 & Gynecology & 10 \\
\hline Urology & 48 & Orthopedics & 7 \\
\hline Cardiology & 21 & Endocrinology & 4 \\
\hline Gastroenterology & 15 & Neurosurgery & 3 \\
\hline Neurology & 11 & Cardiac surgery & 4 \\
\hline Pulmonology & 14 & Otolaryngology & 3 \\
\hline Nephrology & 14 & Dermatology & 2 \\
\hline General surgery & 14 & Rheumatology & 2 \\
\hline
\end{tabular}

\section{Figures}

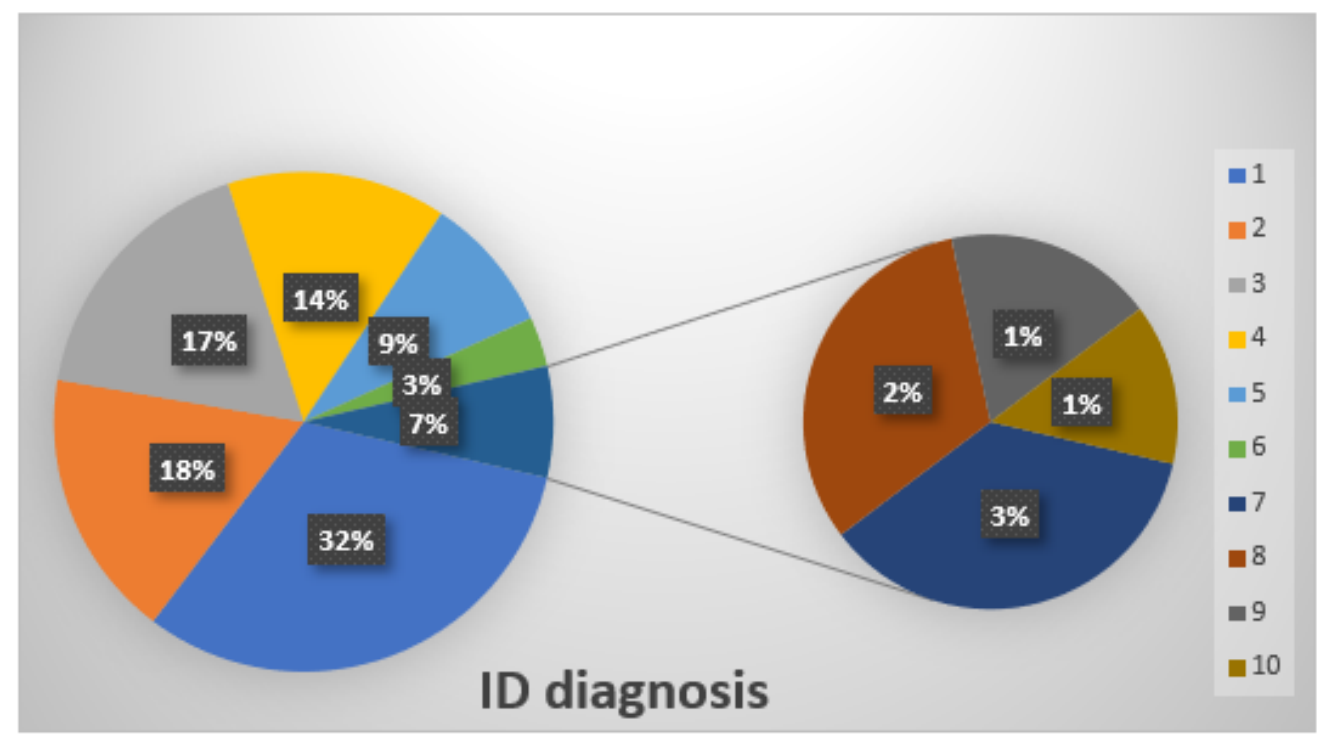

\section{Figure 1}

Chart 1: Shows the ID diagnosis of the 224 patients receiving antibiotics (percentage) 1-Urinary infections; 2Pulmonary and Ear Nose Throat (ENT) infections; 3-Skin and soft tissue infections; 4-Gastrointestinal tract; 5Perioperative prophylaxis; 6-Undetermined infections; 7-Febrile neutropenia; 8-Bacteremia; 9-Neurologic tract infections; 10-Gynecologic tract infections 